\title{
Association patterns of bottlenose dolphins (Tursiops truncatus) in Bahía San Antonio, Argentina
}

Els Vermeulen

Mammal Research Institute Whale Unit, University of Pretoria, cnr Lynnwood Road and Roper Street, Hatfield, South Africa.

Whalefish, 2/10/72 Lancefield Quay, Glasgow G38JF, United Kingdom

Sea Search, 4 Bath Road, Muizenberg, Cape Town South Africa

Contact: elsvermeulen5@gmail.com /+27609714301

\begin{abstract}
This study aims to investigate the association patterns of a small and resident population of bottlenose dolphins (Tursiops truncatus) in Bahía San Antonio (Argentina), and assess any seasonal variation in view of the reported seasonal variation in the population's grouping behavior.
\end{abstract}

The estimation of social differentiation (S) was $0.29(\mathrm{SE}=0.08)$, suggesting a homogenous society. The half-weight index (HWI) averaged $0.23( \pm 0.06)$, with evidence of long-term preferred associations. However, data showed seasonal variation in the association patterns. In winter, when large groups were reported in this population, HWI values averaged $0.30( \pm$ 0.09) with no indication of preferred or avoided associations. However, during summer, when group size was generally small, HWI values averaged $0.14( \pm 0.07)$, with an indication of preferred/avoided associations. 
This study indicates that the social structure of the bottlenose dolphins in Bahía San Antonio seems relatively homogenous and flexible over time, with the formation of a random social network at times when large aggregations are formed, and a more disconnected network made up of strongly connected components when the cost of grouping is high.

Keywords: associations, bottlenose dolphin, fission-fusion society, seasonality, social structure

\section{Introduction}

Being an easily accessible coastal species, the social ecology of common bottlenose dolphin (Tursiops truncatus) communities has been studied in many regions around the world (reviewed by Connor et al. 2000). Generally, research has shown that the species has a fluid social structure (Würsig and Würsig 1979, Ballance 1990, Smolker et al. 1992, Williams et al. 1993, Wilson 1995) often referred to as a fission-fusion society (Würsig and Würsig 1977, Wells et al. 1987, Smolker et al. 1992, Connor et al. 2000). Most detailed information originates from a handful of long term studies (e.g., Wells 1991, Smolker et al. 1992, Connor et al. 2000, Lusseau et al. 2003), which indicate the existence of sexual segregation within the dolphin's society, as well as strong long-term male alliances and strong variability in female association patterns depending on reproductive status (Wells 1991; Connor et al. 1992, 2000; Lusseau et al. 2003). On the other hand, only a few other studies have shown that such strong bonds may not occur in all bottlenose dolphin populations (e.g., Wilson 1995, Bearzi et al. 1997, Foley et al. 2010). Indeed, in fission-fusion societies it is aimed to balance the costs and benefits of grouping related to mating, predation risk, and food availability (Grove et al. 2012). Due to the habitat specific nature of these pressures, fine-scale dissimilarities may 
occur in the grouping behavior and association patterns of different bottlenose dolphin populations (Connor et al. 2000).

Little is known about the social structure of bottlenose dolphins in Argentina. Nonetheless, the study population, located in the north of Patagonia, has been monitored since 2006 and is relatively well known (e.g., Fruet et al. 2014; Vermeulen and Bräger 2015; Vermeulen et al. 2015, 2016). It is a small (approx. 83 individuals) and isolated population (Vermeulen and Bräger 2015), showing high levels of residency and site-fidelity to the area of Bahía San Antonio (Vermeulen et al. 2016). This population also shows a marked seasonal pattern in grouping behavior with significantly larger groups observed in winter $(\bar{X}=7)$ and the smaller groups in summer $(\bar{X}=3$; Vermeulen et al. 2015). The authors suggested this variation was caused by a seasonal variation in food availability, and regulation of feeding competition; i.e., in winter prey seems to be abundant and dolphins are often engaged in cooperative surface feeding activities (in groups of on average 27 individuals, Vermeulen et al. 2015) believed to increase prey capture efficiency (Wells et al. 1980, Würsig and Würsig 1980). On the other hand, in summer prey seems to be scarcer and dolphins are frequently engaged in a "tail-out peduncle dive" foraging behavior in small groups of 2 individuals on average (Vermeulen et al. 2015), believed to be a strategy to reduce scramble competition (Pearson 2009) and increase individual fitness (Würsig 1986).

The aim of this study was to investigate this population's association patterns. Considering the population's seasonal variation in grouping behavior and the influence of grouping on associations (due to the adopted definition as membership of the same group; Whitehead $2008 b$ ), it was furthermore aimed to assess any seasonal variation within the dolphin's social structure. 


\section{Materials and Methods}

\section{Study area and Fieldwork}

Bahía San Antonio (4045’S 645ㄴ W; Fig. 1) is a shallow bay of approximately $200 \mathrm{~km}^{2}$, an average depth of $6 \mathrm{~m}$, and a maximum depth of $30 \mathrm{~m}$ (SHN 2000). The bay is located at the northern end of Golfo San Matías, Patagonian Argentina, and is known for its large tidal differences (Perier 1994, SHN 2000). The area is believed to be the core habitat within the larger home range of a community of bottlenose dolphins (Vermeulen and Cammareri 2009, Vermeulen et al. 2016).

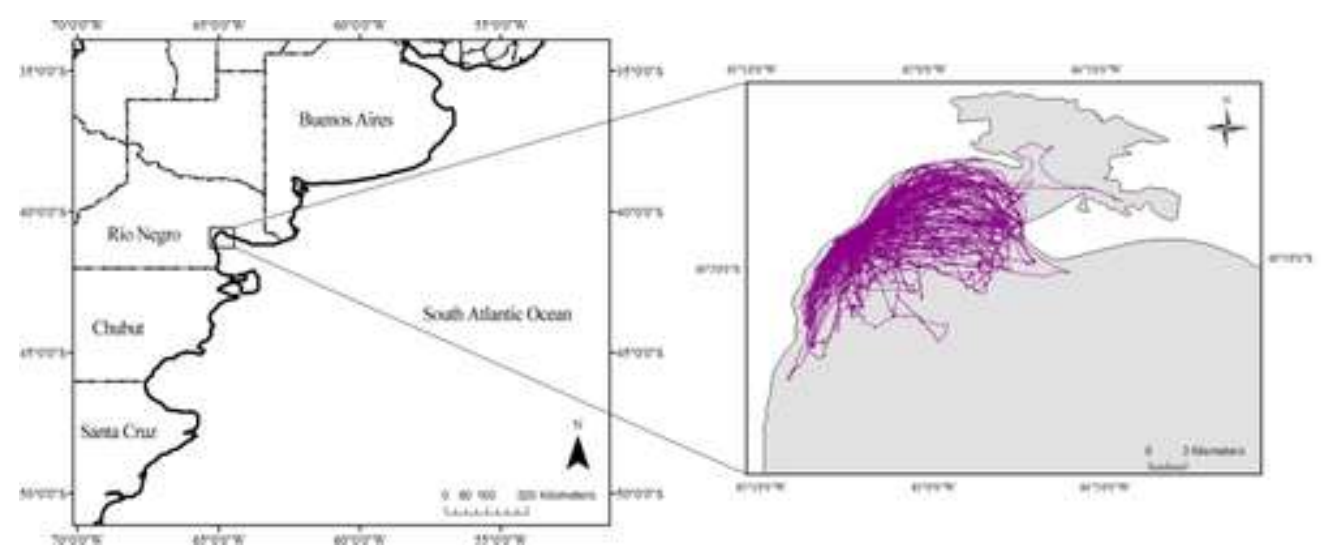

Figure 1. Map of Argentina indicating the provinces, detailing the study area Bahía San Antonio and the boatbased survey tracks

A total of 129 boat-based surveys were conducted from a small outboard-powered inflatable boat between August 2008 and December 2011. The effort totaled 587 h during which 155 dolphin groups were observed. Table 1 presents the distribution of effort over the different years and seasons. 
Table 1. Hours of photo-identification survey effort in Bahía San Antonio (h) and cumulative number of individuals identified over the different years and seasons.

\begin{tabular}{ccccc} 
& Summer & Autumn & Winter & \multicolumn{1}{l}{ Spring } \\
\hline 2008 & Oh $/ 0$ & 0h $/ 0$ & $31 \mathrm{~h} / 91$ & $53 \mathrm{~h} / 44$ \\
2009 & $67 \mathrm{~h} / 67$ & $40 \mathrm{~h} / 46$ & $37 \mathrm{~h} / 73$ & $18 \mathrm{~h} / 36$ \\
2010 & $31 \mathrm{~h} / 18$ & $14 \mathrm{~h} / 16$ & $143 \mathrm{~h} / 220$ & $22 \mathrm{~h} / 26$ \\
2011 & $78 \mathrm{~h} / 89$ & $33 \mathrm{~h} / 15$ & $20 \mathrm{~h} / 74$ & $0 \mathrm{~h} / 0$ \\
TOTAL & $176 \mathrm{~h} / 174$ & $87 \mathrm{~h} / 77$ & $231 \mathrm{~h} / 458$ & $93 \mathrm{~h} / 106$
\end{tabular}

All survey effort was restricted to calm seas of Beaufort state $\leq 3$, periods of no or little precipitation, and good visibility. During each survey, the boat was maintained at a steady speed of 4 - 5 knots, with the same 2 - 3 observers maintaining a continuous visual search for dolphins. The course of the boat-based survey could not be standardized; the area was surveyed nonystematically until a bottlenose dolphin group was found. This was due to logistical limitations, and decisions were made by the skipper based on fuel availability and weather conditions (e.g., if there was strong onshore wind, the course of the survey remained closer to shore, whereas when weather conditions allowed, the survey was conducted more offshore; when fuel availability was low, survey effort had to be decreased). Nonetheless, with each survey we aimed to ensure the best possible coverage of the entire bay.

A dolphin group was defined as a collection of dolphins within a $100 \mathrm{~m}$ radius of each other (Wells et al. 1987) that operated in a coordinated way (Lusseau et al. 2003), interacting or engaged in similar activities (Irvine et al. 1981, Wells et al. 1987, Wilson 1995, Lusseau et al. 2006, Connor et al. 2000). Once a bottlenose dolphin group was encountered, group size was estimated by two researchers independently, and verified subsequently using photographs obtained for photo-identification . 
For each dolphin group encountered, as many high-quality photographs as possible were taken of the dorsal fins of all individuals in the group for later identification of individuals, regardless of the presence of obvious marks (Würsig and Würsig 1977, Würsig and Jefferson 1990). These photographs were taken using a digital DSLR camera Nikon D90 and a $200 \mathrm{~mm}$ Nikor zoom lens (f/2.8) and a 1.7x duplicator. The quality of these photos was graded based on Urian et al. (2015). Dolphins identified to be closely accompanied by a calf on at least two different occasions were assumed to be females (Mann and Smuts 1999, Grellier et al. 2003). In addition, the sex of 14 dolphins was determined through genetic sampling as part of another study (Fruet et al. 2014). Seasons were defined as follows: (1) summer: January to March, (2) autumn: April to June, (3) winter: July to September, (4) spring: October to December.

\section{Data Selection}

All individuals within a group were considered to be associated with each other, a spatial definition of association commonly used in studies of vertebrate social structure (Whitehead and Dufault 1999). The more frequently two dolphins were sighted together in the same group, the more strongly they were associated. Only Q1 and Q2 pictures were used for analysis (Urian et al. 2015). All sightings of groups were selected to be at least a day apart to

ensure independent sampling periods (Bejder et al. 1998; Chilver and Corkeron 2002; Whitehead 2008a,b). Groups sighted on the same day remained in analyses as they were pooled within the same sampling period (see below for details on sampling period). Furthermore, only identified dolphins resighted $\geq 5$ times were selected for social association analysis. Within the data set, this selection procedure was believed to result in a sufficient number of individuals for the analysis (both highly resident and less resident individuals), 
while ensuring the identifiability of the individuals. Calves were excluded from the analysis due to their dependence on their mothers.

\section{Defining Associations and Social Organization}

Half-weight index (HWI) values were calculated using SocProg 2.6, a Matlab program for analyzing social organizations within animal societies (Whitehead 2009, 2015). The HWI was chosen as a measure of association, because it tends to correct for missed identifications of one member of a pair (which is inherent in photo-identification techniques) including withingroup sampling errors and within-community sampling errors (Cairns and Schwager 1987, Ginsberg and Young 1992, Smolker et al. 1992). The HWI can vary from 0.0 for individuals never seen together to 1.0 for individuals always seen together. It has been applied at various times to evaluate the association patterns of bottlenose dolphins (e.g., Wells et al. 1987, Weller 1991, Connor et al. 1992, Smolker et al. 1992, Bräger et al. 1994, Lusseau et al. 2006, Cantor et al. 2012). To calculate the association index values for each dyad (pair of individuals), a daily sampling period was chosen. In order to ensure more than one dolphin group was observed within a sampling period (thus more than one occasion to observe associations), and in view of the spread of the selected data, a monthly sampling period was chosen to perform the permutation test (of groups within samples).

To test the accuracy of representing the true social system (power of analysis), the correlation coefficient $r$ between the true association indices (proportion of time dyads actually spend together, Cairns and Schwager 1987) and the estimated association indices were calculated, using the likelihood approximation (Whitehead 2008a). Values of $r$ close to 1.0 indicate an excellent representation, close to 0.8 indicate a good representation, whereas values close to 0.4 indicate a somewhat representative pattern. Values close to 0.0 indicate no power 
(Whitehead 2008b, 2015). The social organization of the population was analyzed by estimating the 'social differentiation' $(S)$ using the likelihood approximation (including bootstrap standard errors), which is the coefficient of variation of the true association indices (Whitehead 2008a). It is a measure of how varied the social system is; values $<0.3$ indicate a homogeneous society whereas values $>2$ indicate extremely differentiated societies (Whitehead 2015). Subsequently, in order to ensure the statistical power of the permutation test, $S^{2} \mathrm{x} H$ was calculated based on Whitehead (2008a) in which $H$ is the mean number of associations per individual. Sufficient statistical power to reject the null hypothesis of no preferred/avoided associations was assumed when $S^{2} \mathrm{x} H>5($ Whitehead 2008a).

A Monte Carlo randomization technique was employed to test the significance of all possible dyads of animals within the sample by comparing any association pattern in real data with a distribution of random data (Manly 1995, Bejder et al. 1998). This permutation test (of groups within samples) is used to test the null hypothesis that individuals associate at random. Following the methods of Bejder et al. (1998) and Whitehead and Dufault (1999), the number of permutations performed in this test was increased until the $p$ value obtained from the Monte Carlo simulation stabilized and the confidence intervals decreased. This occurred at 20,000 permutations with 1,000 trials per permutation.

Within the permutation test, short-term (within sampling periods) preferred/avoided associations are indicated by a significantly lower mean of the observed $v s$. random association index (for more detail see Whitehead et al. 2005, Whitehead 2008b). Additional evidence for the presence of avoided associations is found when this decrease of the proportion of non-zero association index values is significant when comparing the observed vs. random data (Whitehead 2008b). In general, long-term (between sampling periods) 
preferred/avoided associations are indicated by a significantly higher Standard deviation (SD) and coefficient of variation $(\mathrm{CV})$ of the observed vs. random association index values (Whitehead et al. 2005).

To assess differences in association by sex, a Mantel test (Mantel 1967) was carried out. The statistical significance of each Mantel test was tested against the null hypothesis in which the number of preferred associations was unrelated to the sex, using 1,000 random permutations. To validate the use of HWI vs. HWIG (Half Weight Index standardized for gregariousness; for more detail, see Godde et al. 2013) to assess association patterns, a variation in individual gregariousness was tested. This test searches for individuals that may be consistently found in groups larger or smaller than the typical (Jarman 1974, Whitehead et al. 2005). The null hypothesis is that all individuals are found in groups with a similar size distribution, and it is rejected when the SD of the typical group size (tgs: mean group size for any given individual) is unexpectedly high and significantly different from the permutated data (Whitehead 2015). When the variation in individual gregariousness is unsubstantial compared to the variation in affinity, the HWI is believed to be suitable for the assessment of association patterns, with no need to standardize for gregariousness (see Godde et al. 2013).

All data were analyzed in combination across seasons as well as for each season separately.

\section{Temporal association pattern}

In order to examine the temporal stability of associations between individuals, the standardized lagged association rate (SLAR) was calculated. This is appropriate relative to the lagged association rate when potentially not all associates are recorded on every monitoring occasion (Whitehead 1995). The precision of this process was estimated by jackknifing over 
the sampling periods (Efron and Stein 1981). The resulting proportion was then compared to the null association rate (Whitehead 1995) which represents the association rate over time if individuals are associating at random with no preferred companions. The rate of decay of the SLAR was then compared with a number of mathematical models describing different rates of exponential decay (see Whitehead 1995). The Quasi Akaike Information Criteria (QAIC) was used to select the model with the lowest theoretical expected error (Whitehead 2008b), which then provided an estimate of the decay of associations. For this analysis, no data selection was performed to avoid a positive bias (Whitehead 2008b); i.e., 155 groups and 64 identified individuals were used for this analysis.

\section{Results}

After data selection, 116 groups were selected for analysis of the social organization. Out of these groups, 57 identified dolphins seen $\geq 5$ times were selected. Twelve of these individuals were males and 15 were females; the remaining 30 individuals were of unknown sex.

\section{Social Organization}

The correlation coefficient $r$ between the true association indices and the calculated association indices was $0.73(\mathrm{SE}=0.03)$, suggesting a relatively good representation of the true social structure. The estimation of social differentiation $(\mathrm{S})$ resulted 0.29 ( $\mathrm{SE}=0.08$ ), indicating a rather homogenous society (i.e., no apparent differentiated social groups within the population). The mean number of observed associations per individual (H) was 209.73. Based on guidelines developed by Whitehead (2008a), the data appear to have the power to reject the null hypothesis of preferred or avoided associations $\left(\mathrm{S}^{2} \times \mathrm{H}=0.29^{2} \times 209.73=17.6\right.$ $>5$ ). When subdividing the data set per season, the correlation coefficient ( $r$ ) dropped to 0.64 $(\mathrm{SE}=0.06)$ for winter and $0.58(\mathrm{SE}=0.06)$ for summer, suggesting data were still somewhat 
representative of the true social system, although for summer the representation is weak. Due to the low social differentiation in winter $(S=0.20)$ (and thus the need for more observed associations; Whitehead 2008a), the power to reject the null hypothesis of no preferred/avoided associations is weak $\left(\mathrm{S}^{2} \times \mathrm{H}=0.20^{2} \times 148.04=5.9>5\right)$. On the other hand, due to the higher social differentiation in summer $(S=0.72)$ (and thus the need for fewer observed associations; Whitehead 2008a), there appears to be strong power to reject the null hypothesis of no preferred/avoided associations $\left(\mathrm{S}^{2} \times \mathrm{H}=0.72^{2} \times 35.7=18.5>5\right)$. Based on similar calculations, separate data sets for autumn and spring were excluded from further analyses.

The HWI value for all possible dyads $(n=1596)$ averaged $0.23( \pm 0.06 \mathrm{SD})$, whereas the maximum HWI value averaged $0.50( \pm 0.08 \mathrm{SD})$. The HWI values varied over the two seasons, with the lowest average HWI value found in summer and the highest one in winter. Table 2 provides a summary.

Table 2. Average half-weight index values (HWI) with SD as well as average of maximum HWI values with SD for all individuals calculated in general as well as for the seasons. The number of possible dyads and the amount of dyads for which the HWI > 0 (number of non-zero dyads) are also given. The separate datasets that were not accepted with sufficient power of analysis to detect the true social system, and thus excluded from further analyses, are written between brackets (see text for further details).

\begin{tabular}{cccccccc} 
& & $\begin{array}{c}\text { Average } \\
\text { HWI for } \\
\text { all dyads }\end{array}$ & SD & $\begin{array}{c}\text { Average } \\
\text { of } \\
\text { maximum } \\
\text { HWI of } \\
\text { all dyads }\end{array}$ & SD & $\begin{array}{c}\text { Number of } \\
\text { non-zero } \\
\text { dyads }\end{array}$ & $\begin{array}{c}\text { Number } \\
\text { of } \\
\text { possible } \\
\text { dyads }\end{array}$ \\
\hline \multirow{3}{*}{ Season } & Total & 0.23 & 0.06 & 0.50 & 0.08 & 1468 & 1596 \\
& Summer & 0.14 & 0.07 & 0.62 & 0.19 & 486 & 1081 \\
& (Autumn) & $(0.14)$ & $(0.07)$ & $(0.63)$ & $(0.19)$ & $(213)$ & $(561)$ \\
& Winter & 0.30 & 0.09 & 0.61 & 0.12 & 1420 & 1596 \\
& (Spring) & $(0.22)$ & $(0.10)$ & $(0.86)$ & $(0.15)$ & $(406)$ & $(946)$ \\
\hline
\end{tabular}


Results of the permutation test (using a monthly sampling period; see Table 3) showed that the observed mean association index was not significantly different from the random mean, indicating that the null hypothesis of no short-term preferred companions could not be rejected. However, the null hypothesis of no long-term preferred associations could be rejected based on the available data (observed SD and CV significantly larger than random SD and CV; Table 3). The test further indicated that the null hypothesis of all individuals being found in groups with a similar size distribution (gregariousness) could not be rejected, as the SD of the tgs was relatively low and showed no difference when compared to the permuted data. This suggests that there was no need to standardize for gregariousness (i.e., use of HWIG).

A permutation test was subsequently performed for data from winter and summer separately (i.e., winter associations of all study years combined; see Table 3). Results indicated that in winter, the null hypothesis of no preferred/avoided companions (short- and long-term) could not be rejected (observed mean, $\mathrm{SD}, \mathrm{CV}$ and proportion of non-zero association index values did not differ from the random values). However, in summer such null hypothesis was rejected, with indications for both short- and long-term preferred (observed SD and CV > random SD and CV) and avoided (observed proportion of non-zero association index value < random proportion of non-zero association index value) associations. Results of the test further showed that regardless of season, the null hypothesis of all individuals being found in groups with a similar size distribution could not be rejected (observed $\mathrm{SD}(\operatorname{tgs})=$ random $\mathrm{SD}(\operatorname{tgs}) ;$ Table 3$)$. 
Table 3. Results of the permutation test of the overall Half Weight Index values (HWI), and those for winter and summer. $\mathrm{CV}=$ coefficient of variation, $\mathrm{SD}=$ standard deviation, tgs = typical group size. $\mathrm{P}$ values are given in Italic. * indicates significant $P$ values

\begin{tabular}{|c|c|c|c|}
\hline & $\begin{array}{l}\text { Overall } \\
\text { HWI }\end{array}$ & $\begin{array}{l}\text { Winter } \\
\text { HWI }\end{array}$ & $\begin{array}{c}\text { Summer } \\
\text { HWI }\end{array}$ \\
\hline Observed mean & 0.29 & 0.44 & 0.18 \\
\hline Random mean & 0.29 & 0.44 & 0.19 \\
\hline (Test for presence of short-term preferred/avoided associations) $P$ & 0.39 & 0.51 & $<0.01 *$ \\
\hline Observed SD & 0.15 & 0.23 & 0.24 \\
\hline Random SD & 0.15 & 0.23 & 0.22 \\
\hline (Good test for presence of long-term preferred associations) $P$ & $<0.05 *$ & 0.30 & $<0.01 *$ \\
\hline Observed CV & 0.53 & 0.53 & 1.35 \\
\hline Random CV & 0.50 & 0.52 & 1.19 \\
\hline (Preferred test for presence of long-term preferred associations) $P$ & $<0.05 *$ & 0.34 & $<0.01 *$ \\
\hline Observed proportion non-zero association index values & 0.93 & 0.89 & 0.42 \\
\hline Random proportion non-zero association index values & 0.93 & 0.89 & 0.48 \\
\hline (Additional test for presence of avoided associations) $P$ & 0.13 & 0.29 & $<0.01 *$ \\
\hline Observed SD of non-zero association index values & 0.13 & 0.18 & 0.19 \\
\hline Random SD of non-zero association index values & 0.13 & 0.18 & 0.16 \\
\hline$P$ & $<0.05 *$ & 0.41 & $<0.01 *$ \\
\hline Observed SD (tgs) & 2.94 & 4.06 & 2.52 \\
\hline Random SD (tgs) & 2.50 & 3.6 & 2.43 \\
\hline (Test for variation in individual gregariousness) $P$ & 0.15 & 0.11 & 0.35 \\
\hline
\end{tabular}

Associations between and within sex were not significantly different within the whole data set (Mantel test: $t=-1.75 ; P=0.07)$. Additionally, only 9 dyads $(0.5 \%$ of all possible dyads or $0.6 \%$ of all non-zero dyads) associated significantly more or less than expected at random over the total duration of the study (Table 4). No difference in dyad distribution (individuals associating more or less than expected) could be found in winter or spring when compared to the overall data set. 
Table 4. Number of dyads associating significantly different from random over the entire study period, depending on sex classes. The total number of possible dyads and the number of non-zero dyads $(\mathrm{HWI}>0)$ is also given for each dyad category

\begin{tabular}{lcccc} 
& $\begin{array}{c}\text { Less than } \\
\text { expected } \\
(p<0.025)\end{array}$ & $\begin{array}{c}\text { More } \\
\text { than } \\
\text { expected } \\
(p>0.975)\end{array}$ & $\begin{array}{c}\text { Total } \\
\text { possible } \\
\text { dyads }\end{array}$ & $\begin{array}{c}\text { Number } \\
\text { of non- } \\
\text { zero } \\
\text { dyads }\end{array}$ \\
\hline Male-male & 0 & 0 & 66 & 66 \\
Female-female & 1 & 0 & 105 & 98 \\
Male-female & 0 & 0 & 180 & 173 \\
\hline Male-unknown gender & 0 & 1 & 360 & 345 \\
Female-unknown gender & 5 & 0 & 450 & 396 \\
Unknown gender-unknown gender & 2 & 0 & 435 & 387 \\
\hline Total & 8 & 1 & 1596 & 1465
\end{tabular}

\section{Temporal Association Pattern}

The general SLAR shows a fluctuation in the duration of associations, but shows little decay over the entire study period (Fig. 2). The model with the lowest QAIC value included preferred companions and casual acquaintances (represented by the function $a 2+a 3^{*} \exp (-$ a1*td)). The fitted values from this model suggest a quick decrease of the SLAR over the first $2-3$ mo, with values stabilizing at around 0.022 , remaining slightly higher than the predicted random (Null) association rate, which indicates the existence of a small proportion of longterm associations (as observed in the permutation test). The duration of casual acquaintances was estimated at $23 \mathrm{~d}$, given by $1 / \mathrm{a} 1(\mathrm{a} 1=1.2649(\mathrm{SE}=0.019))$. 


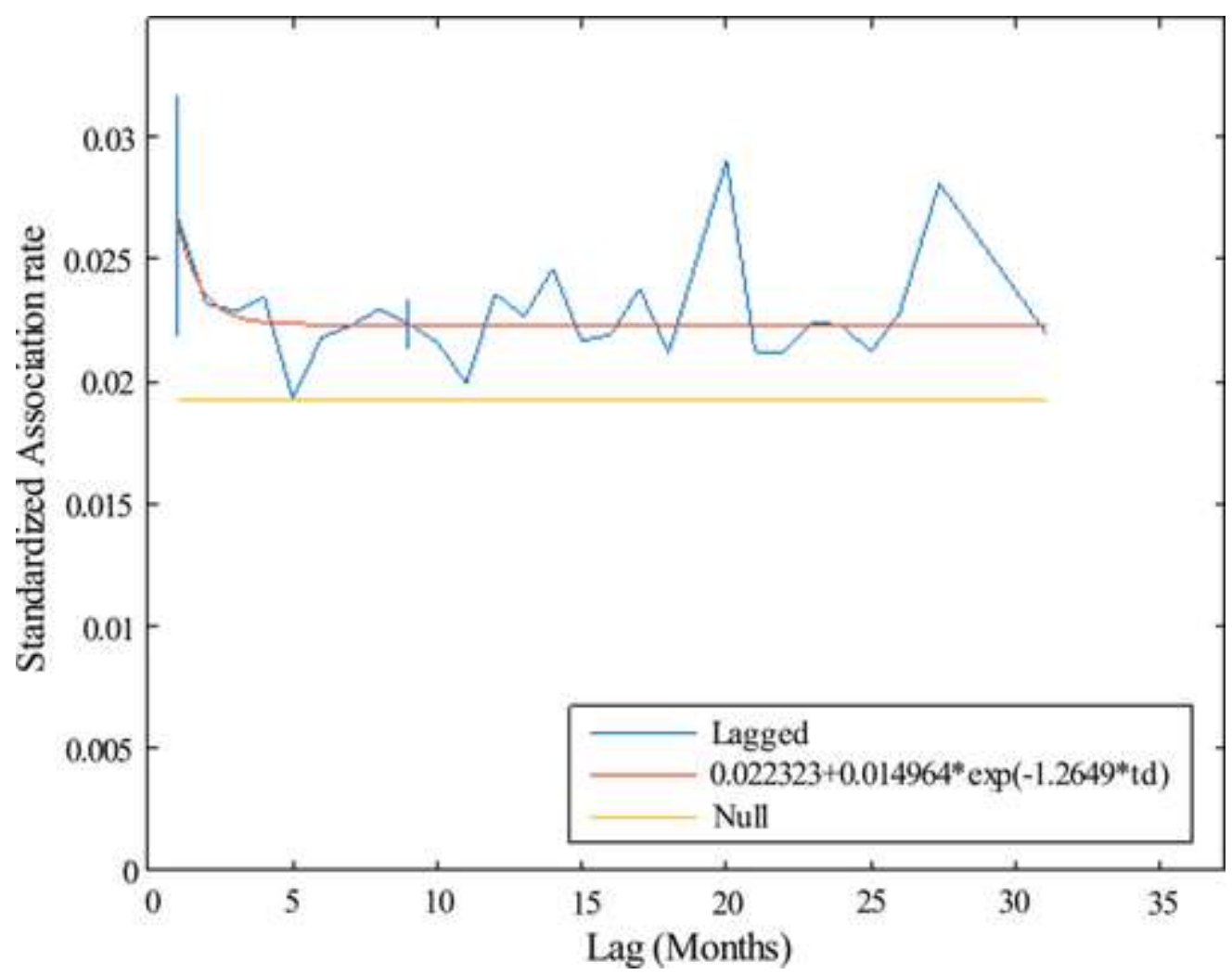

Figure 2. Standardized Lagged Association Rate for pairs of bottlenose dolphins associated within groups in Bahía San Antonio; the plot shows the probability of associations persisting after increasing lags in time between observations (Lag). The null association rate (Null) is the expected value of the lagged association rate if there are no preferred associations. It is the inverse of the population size minus one, and so does not change with time lag. Bars represent the SE estimated using the jackknifing procedure. The maximum-likelihood best-fit model represents associations with preferred companions and casual acquaintances represented by the function $0.022323+0.014964 * \exp (-1.2649 * \mathrm{td})$

\section{Discussion}

The results suggest that the bottlenose dolphins in Bahía San Antonio live in a rather homogenous and flexible fission-fusion society with a few long-lasting associations. The overall average association index value (HWI) is well within the range of the values found in common bottlenose dolphin populations worldwide (e.g. Smolker et al. 1992, Bräger et al. 1994, Wilson 1995, Rossbach and Herzing 1999, Connor et al. 2000, Blasi et al. 2014). 
Despite the limitations of the low sample size, the rate of associations seemed to vary between winter and summer, similarly to the dolphin's grouping behavior in these respective seasons (ref. Vermeulen et al.2015). As such, in winter when average group size was reported to be largest $(\bar{X}=7$ individuals; Vermeulen et al. 2015), most associations were formed (89\% of all possible dyads) and the average HWI value reached its maximum of 0.30 . Results further indicate that the null hypothesis of no preferred or avoided associations could not be rejected. However, because the statistical power was weak, one must be careful not to assume there are no preferred/avoided associations at this time of year. On the other hand, during summer when average group size was reported to be at its minimum $(\bar{X}=3$ individuals; Vermeulen et al. 2015), least associations were formed (45\% of all possible dyads) and HWI dropped accordingly to a minimum of 0.14 . Results further showed that during this season, the null hypothesis of no preferred or avoided associations could be rejected.

These results suggest that the bottlenose dolphins in Bahía San Antonio exhibit a temporal variability in their association rates, as also shown in the Standardized Lagged Association Rate. When the benefit of grouping is high (e.g., to increase capture efficiency when food is abundant or when predation pressure is high) and larger aggregations are formed (in this study population during winter; Vermeulen et al. 2015), it appears that a social network arises in which individuals engage in numerous and short-lived associations (Clapham 1996). On the other hand, when the cost of grouping is high (e.g., when food availability is low) in this study population during summer (Vermeulen et al. 2015), it seems a more disconnected network arises with individuals engaging with few yet long-lasting associations (Cantor et al. 2012). Within this study, such variation in grouping behavior seemed to be equal for all individuals included in analysis, as no individual variation in gregariousness could be found. 
Such temporal shift in associations has been shown before in other fission-fusion societies (e.g., chitals, Axis axis: Raman 1997; African elephants, Loxodonta sp.: Wittemyer et al. 2005; bottlenose dolphins: Connor et al. 2000), and has mostly been related to socioecological and/or demographic factors (e.g., Aureli et al. 2008, Parsons et al. 2009, Foster et al. 2012, Pinter-Wollman et al. 2013). Vermeulen et al. (2015) suggested that the seasonal variation in grouping behavior of the studied population was related to a seasonal variation in food availability and the Ecological Constraints Hypothesis (Chapman 1990). Although no empirical data are available in this study to assess this hypothesis, a handful of studies have shown such a relation in other cetacean societies. For example, Foster et al. (2012) showed how resource availability is an important determinant of the social structure of killer whales (Orcinus orca). Sociality increased when food was abundant, and a less connected social network occurred when food was less abundant (Foster et al. 2012). Pearson (2009) indicated that coordinated foraging strategies are the primary influence on the fission-fusion dynamics of dusky dolphins (Lagenorhynchus obscurus). Chilvers and Corkeron (2002) reported how bottlenose dolphin social structure in Moreton Bay was related to the presence of trawlers and the associated foraging technique of certain individuals. About a decade later, Ansmann et al. (2012) indicated how the same dolphins restructured their social organization when these trawlers disappeared. On the other hand, one cannot exclude the effect of other aspects such as demography (e.g., age, sex, reproductive status) and previous social experience (Aureli et al. 2008, Pearson 2009, Pinter-Wollman et al. 2013). For example, the social structure of northern bottlenose whales (Hyperoodon ampullatus) does not appear to be driven by their deep-diving foraging strategy (Gowans et al. 2001). Undeniably, the social structure of a population should be seen as a multivariate optimization to various pressures, and does not result from one ultimate cause (Caraco 1979). 
The common bottlenose dolphin is often believed to live in strongly defined social organizations, with the presence of many strong long-term male alliances and strong associations between females depend on reproductive status (Wells 1991; Connor et al. 1992, 2000; Lusseau et al. 2003). Furthermore, it is frequently argued that in small bottlenose dolphin communities, with high site-fidelity to a small area, cohesiveness increases (Connor et al. 2000, Lusseau et al. 2003, Augusto et al. 2011) as there are only a small number of possible associates for each individual (Bräger 1999). However, despite the study population being small, isolated and highly resident in the study area (Vermeulen and Bräger 2015, Vermeulen et al. 2016), results showed that its social structure is not as strongly defined as often assumed for the species. In fact, it is homogenous and flexible, reconfirming the species' potential for a high degree of fission-fusion dynamics (Aureli et al. 2008) to adapt to fine-scale variations in temporal and habitat-specific pressures on grouping and association patterns (e.g., Lusseau et al. 2003, Karczmarski et al. 2005, Elliser and Herzing 2011).

\section{Acknowledgments}

Thanks are due to Alejandro Cammareri for his help during the surveys, and the Marybio Foundation of which I was part over the course of this study. Many thanks go to Mariela Pazos, Jorge Baraschi, Hernan David, Claudio Barbieri, Perdo Fruet, and many others for their help over the years. Thanks to the Consejo de Ecología y Medio Ambiente de Río Negro (CODEMA) and the Dirección de Fauna Silvestre de Río Negro for the necessary research permits. This study was funded by Cetacean Society International, Trigon N.V. and the Marybio Foundation. This manuscript was improved thanks to the reviews of Stefan Bräger, Rodrigo Genoves, and five reviewers. 


\section{Literature cited}

Ansmann, I. C., G. J. Parra, B. L. Chilvers and J. M. Lanyon. 2012. Dolphins restructure social system after reduction of commercial fisheries. Animal Behaviour 84:575-581. DOI: 10.1016/j.anbehav.2012.06.009.

Augusto, J. F., P. Rachinas-Lopes, and M. E. dos Santos. 2011. Social structure of the declining resident community of common bottlenose dolphins in the Sado Estuary, Portugal. Journal of the Marine Biological Association of the United Kingdom 1:1-10.

Aureli, F., C. M. Schaffner, C. Boesch C, et al. 2008. Fission-Fusion Dynamics. Current Anthropology 49:627-654.

Ballance, L.T. 1990. Residence patterns, group organization, and surfacing associations of bottlenose dolphins in Kino Bay, Gulf of California, Mexico. Pages 267-283 in Leatherwood, S. and Reeves, R.R., eds. The bottlenose dolphin. Academic Press, San Diego, CA.

Bearzi, G., G. Notarbartolo di Sciara, and E. Politi. 1997. Social ecology of bottlenose dolphins in the Kvarneric' (Northern Adriatic sea). Marine Mammal Science 13: 650-668.

Bejder, L., D. Fletcher and S. Bräger. 1998. A method for testing association patterns of social animals. Animal Behaviour 56:719-772.

Blasi, M. F., and L. Boitani. 2014. Complex social structure of an endangered population of bottlenose dolphins (Tursiops truncatus) in the Aeolian Archipelago (Italy). PloS one 9: e114849. DOI: 10.1371/journal.pone.0114849. 
Bräger, S. 1999. Association patterns in three populations of Hector's dolphin, Cephalorhynchus hectori. Canadian Journal of Zoology 77:13-18.

Bräger, S., B. Würsig, A. Acevedo and T. Henningsen. 1994. Association patterns of bottlenose dolphins (Tursiops truncatus) in Galveston Bay, Texas. Journal of Mammalogy 75:431-437.

Cairns, S. J., and S. J. Schwager. 1987. A comparison of association index values. Animal Behaviour 35:1454-1469.

Cantor, M., L. L. Wedekin, P. R. Guimarães, F. G. Daura-Jorge, M. R. Rossi-Santos and P. C. Simões-Lopes. 2012. Disentangling social networks from spatiotemporal dynamics: the temporal structure of a dolphin society. Animal Behaviour 84:641-651.

Caraco, T. 1979. Time budgeting and group size: a test of theory. Ecology 60:618-627.

Chapman, C. A. 1990. Ecological constraints on group size in three species of neotropical primates. Folia Primatologica 55:1-9.

Chilvers, B. L., and P. J. Corkeron. 2002. Trawling and bottlenose dolphins'social structure. Procedures of the Royal Society of London B 268: 1901e1905.

Clapham, P. J. 1996. The social and reproductive biology of humpback whales: an ecological perspective. Mammal Review 26: 27e49. 
Connor, R. C., R. A. Smolker and A. F. Richards. 1992. Two levels of alliance formation among male bottlenose dolphins (Tursiops sp.). Proceeding of the National Academy of Sciences USA 89:987-990.

Connor, R. C., R. S. Wells, J. Mann and A. J. Read. 2000. The bottlenose dolphin. Social relationships in a fission-fusion society. Pages 91-126 in Mann, J., R. C. Connor, P. L. Tyack and H. Whitehead, eds. Cetacean Society, Field studies of dolphins and whales. University of Chicago Press. Chicago and London.

Efron, B., and C. Stein. 1981. The jackknife estimate of variance. Annual Statistics 9:586596.

Elliser, C. R. and D. L. Herzing. 2011. Replacement dolphins? Social restructuring of a resident pod of Atlantic bottlenose dolphins, Tursiops truncatus, after two major hurricanes. Marine Mammal Science 27:39-59.

Foley, A., D. McGrath, S. Berrow, and H. Gerritsen. 2010. Social structure within the bottlenose dolphin (Tursiops truncatus) population in the Shannon Estuary, Ireland. Aquatic Mammals 36:372-381.

Foster, E. A., D. W. Franks, L. J. Morrell, K. C. Balcomb, K. M. Parsons, A. van Ginneken and D. P. Croft. 2012. Social network correlates of food availability in an endangered population of killer whales, Orcinus orca. Animal Behaviour 83:731-736. doi: 10.1016/j.anbehav.2011.12.021. 
Fruet, P., E. R. Secchi, F. Daura-Jorge, et al. 2014. Remarkably low genetic diversity and strong population structure in common bottlenose dolphins (Tursiops truncatus) from coastal waters of the Southwestern Atlantic Ocean. Conservation Genetics Doi: 10.1007/s10592-0140586-Z

Ginsberg, J. R., and T. P. Young. 1992. Measuring association between individuals or groups in behavioural studies. Animal Behaviour 44:377-379.

Godde, S., L. Humbert, S. D. Côté, D. Réale and H. Whitehead. 2013. Correcting for the impact of gregariousness in social network analyses. Animal Behaviour 85:553-558.

Gowans, S., H. Whitehead and S. K. Hooker. 2001. Social organisation in northern bottlenose whales, Hyperoodon ampullatus: not driven by deep-water foraging. Animal Behaviour 62:369-377.

Grellier, K., P. S. Hammond, B. Wilson, C. A. Sanders-Reed, and P. M. Thompson. 2003. Use of photo-identification data to quantify mother-calf association patterns in bottlenose dolphins. Canadian Journal of Zoology 81:1421-1427.

Grove, M., E. Pearce and R. I. Dunbar. 2012. Fission-fusion and the evolution of hominin social systems. Journal of Human Evolution 62:191-200. 
Irvine, A. B., M. D. Scott, R. S. Wells and J. H. Kaufmann. 1981. Movements and activities of the Atlantic bottlenose dolphin, Tursiops truncatus, near Sarasota, Florida. Fishery Bulleting 79:671-688.

Jarman, P. J. 1974. The social organization of antelope in relation to their ecology. Behaviour 48:215-267.

Karczmarski, L., B. Würsig, G. Gailey, K. W. Larson and C. Vanderlip. 2005. Spinner dolphins in a remote Hawaiian atoll: social grouping and population structure. Behavioral Ecology 16:675-685.

Lusseau, D., C. Schneider, O. J. Boisseau, P. Haase, E. Slooten and S. M. Dawson. 2003. The bottlenose dolphin community of Doubtful Sound features a large proportion of long-lasting associations. Can geographic isolation explain this unique trait? Behavioral Ecology and Sociobiology 54:396-405.

Lusseau, D., B. Wilson, P. Hammond, et al. 2006. Quantifying the influence of sociality on population structure in bottlenose dolphins. Journal of Animal Ecology 75:14-24.

Manly, B. F. J. 1995. A note on the analysis of species co-occurrences. Ecology 76:11091115.

Mann, J., and B. Smuts. 1999. Behavioural development in wild bottlenose dolphin newborns (Tursiops sp.). Behaviour 136:529-566. 
Mantel, N. A. 1967. The detection of disease clustering and a generalized regression approach. Cancer Research 27:209-220.

Parsons, K. M., K. C. Balcomb, J. K. B. Ford and J. W. Durban. 2009. The social dynamics of southern resident killer whales and conservation implications for this endangered population. Animal Behaviour 77:963-971.

Pearson, H. C. 2009. Influences on dusky dolphin (Lagenorhynchus obscurus) fission-fusion dynamics in Admiralty Bay, New Zealand. Behavioral Ecology and Sociobiology 63:14371446.

Perier, M. R. 1994. La fauna íctica en el litoral de la Bahía de San Antonio (Golfo San Matias, Provincia de Río Negro) [Fish fauna of coastal Bahia San Antonio (San Matias Gulf, Rio Negro Province)]. PhD Dissertation, Facultad de Ciencias naturales y Museo, Universidad Nacional de La Plata, Argentina. 175 pp.

Pinter-Wollman, N., E. A. Hobson, J. E. Smith, et al. 2013. The dynamics of animal social networks: analytical, conceptual, and theoretical advances. Behavioural Ecology art047 doi:10.1093/beheco/art047.

Raman, T. R. S. 1997. Factors influencing seasonal and monthly changes in the group size of chital or axis deer in southern India. Journal of Bioscience 22: 203e218. 
Rossbach, K. A., and D. L. Herzing. 1999. Inshore and offshore bottlenose dolphin (Tursiops truncatus) communities distinguished by association patterns near Grand Bahama Island, Bahamas. Canadian Journal of Zoology 77:581-593.

SHN 2000. Derrotero Argentino, parte II: Costa del Atlentico. Servicio de Hydrografía Naval, Armada de la Republica Argentina (Argentine Navy), Buenos Aires, Argentina.

Smolker, R. A., A. F. Richards, R. C. Connor and J. W. Pepper. 1992. Sex differences in patterns of associations among Indian Ocean bottlenose dolphins. Behaviour 123:38-69.

Urian, K., A. Gorgone, A. Read, et al. 2015. Recommendations for photo-identification methods used in capture-recapture models with cetaceans. Marine Mammal Science 31:298321.

Vermeulen, E., and S. Bräger. 2015. Demographics of the disappearing bottlenose dolphin in Argentina: A common species on its way out? PLoS ONE 10(3): e0119182. doi:10.1371/journal.pone.0119182.

Vermeulen, E., and A. Cammareri. 2009. Residency Patterns, Abundance and Social composition of Bottlenose Dolphins (Tursiops truncatus) in Bahía San Antonio, Patagonia, Argentina. Aquatic Mammals 35:379-386.

Vermeulen, E., L. Holsbeek and K. Das. 2015. Diurnal and seasonal variation in the behaviour of bottlenose dolphins (Tursiops truncatus) in Bahía San Antonio, Patagonia, Argentina. Aquatic Mammals 41:272-283. DOI 10.1578/AM.41.3.2015.272. 
Vermeulen, E., A. Balbiano, F. Beleguer, D. Colombil, M. Failla, E. Intrieri and S. Bräger. 2016. Site-fidelity and movement patterns of bottlenose dolphins in central Argentina: essential information for effective conservation. Aquatic Conservation DOI: 10.1002/aqc.2618.

Weller, D. W. 1991. The social ecology of Pacific coast bottlenose dolphins. MSc Dissertation, San Diego State University, San Diego, CA. 93 pp.

Wells, R. S., A. B. Irvine and M. D. Scott. 1980. The social ecology of inshore odontocetes. Pages 263-317 in Herman L. M. ed. Cetacean behaviour: Mechanisms and processes. New York: John Wiley \& Sons.

Wells, R. S., M. D. Scott and A. B. Irvine. 1987. The social structure of free-ranging bottlenose dolphins. Pages 246-305 in Genoways, H. H., ed. Current Mammalogy. Plenum Press, New York.

Wells, R. S. 1991 The role of long-term study in understanding the social structure of a bottlenose dolphin community. Pages 199-225 in Pryor, K. and K. S. Norris., eds. Dolphin societies: Discoveries and puzzles. University of California Press, Berkeley, CA.

Whitehead, H. 1995. Investigating structure and temporal scale in social organizations using identified individuals. Behavioral Ecology 6:199-208. 
Whitehead, H. 2008a. Precision and power in the analysis of social structure using associations. Animal Behaviour 75:1093-1099.

Whitehead, H. 2008b. Analyzing animal societies: quantitative methods for vertebrate social analysis. University of Chicago Press Chicago.

Whitehead, H. 2009. SOCPROG programs: Analyzing animal social structures. Behavioral Ecology and Sociobiology 63:765-778.

Whitehead, H. 2015. SOCPROG 2.6 Programs for analyzing social structure. Dalhousie University, Nova Scotia. http://whitelab.biology.dal.ca/SOCPROG/social.htm

Whitehead, H., and S. Dufault. 1999. Techniques for analysing vertebrate social structure using identified individuals: Review and recommendations. Advances in the Study of Behavior 28:33-74.

Whitehead, H., L. Bejder and C. A. Ottensmeyer. 2005. Testing association patterns: issues arising and extensions. Animal Behaviour 69:e1-e6.

Williams, J. A., S. M. Dawson and E. Slooten. 1993. The abundance and distribution of bottlenose dolphins (Tursiops truncatus) in Doubtful Sound, New Zealand. Canadian Journal of Zoology 71:2080-2088. 
Wilson, B. 1995. The ecology of bottlenose dolphins in the Moray Firth, Scotland: a population at the northern extreme of the species' range. PhD Dissertation, Faculty of Biological Science, University of Aberdeen. 191 pp.

Wittemyer, G., I. Douglas-Hamilton and M. Getz. 2005. The socioecology of elephants: analysis of the processes creating multitiered social structures. Animal Behaviour 69:13571371.

Würsig, B. 1986. Delphinid foraging strategies. Pages 347-359 in Schusterman, R. J., J. A. Thomas and F. G. Wood, eds. Dolphin cognition and behaviour: a comparative approach. Lawrence Erlbaum Association, Hillsdale, NJ.

Würsig, B., and M. Würsig. 1977. The photographic determination of group size, composition and stability of coastal porpoises (Tursiops truncatus). Science 198:755-756.

Würsig, B., and M. Würsig. 1979. Behaviour and ecology of the bottlenose dolphin (Tursiops truncatus) in the south Atlantic. Fishery Bulletin 77:399-412.

Würsig B., and M. Würsig. 1980. Behavior and ecology of the dusky dolphin, Lagenorhynchus obscurus, in the South Atlantic. Fisheries Bulletin 77: 871-890

Würsig, B., and T. A. Jefferson. 1990. Methods of photo-identification for small cetaceans. Pages 43-52 in Hammond, S., S. A. Mizroch and G. P. Donovan, eds. Use of PhotoIdentification and Other Techniques to Estimate Population Parameters. Report to the International Whaling Commission special issue 12. 